\title{
Advanced Healthcare: A Look At The Current Online Trends
}

S. Altan Erdem, (erdem@cl.uh.edu), University of Houston-Clear Lake Dianne Love, University of Houston-Clear Lake

\begin{abstract}
Since it took a while to recognize the significance of marketing in the field of healthcare, one could have doubts when it comes to the use of the Internet in healthcare marketing. Yet, the growing use of the Internet in healthcare supports the notion that the Internet is probably the most powerful vehicle for distributing health information to millions of individuals and it is one of the best marketing tools in this field. Accordingly, we are now witnessing so many practices that we can safely assume that it is now the time for e-commerce in healthcare industry. While this may be true for many, there are also some who are concerned about using the online options in the field of healthcare. Since these concerns are mostly about the questionable accuracy of the "health" information on the net, they are rather serious and deserve an in-depth look. This paper reviews some of the current practices in the field and provides some examples of "good" and "not-so-good" online options. It is hoped that the review of these examples will result in similar inquiries in the future and as these "not-so-good" options are exposed more, they will eventually be replaced with the "good" ones.
\end{abstract}

\section{INTRODUCTION}

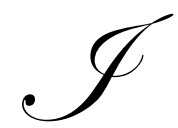

$\mathrm{t}$ is reported that the number of Internet users has increased more than nineteen fold in the last five years (Vijayaraman and Bhatia 2002). It is a fact that Internet use is gaining acceptance by more and more businesses as a viable tool. Given that healthcare industry consumes about $13.5 \%$ of the gross domestic product in the U.S. (Gardner 2000), it is not surprising that Internet use has been gaining acceptance specifically within the healthcare industry. There are over 100,000 health-related websites and this number is climbing rapidly. Interestingly, physician websites are becoming commonplace in the world of healthcare (Morahan-Martin 2004). A recent survey shows that more than 30\% of practicing US physicians report having a practice website (Bard 2003). Furthermore, the number of hospitals using the Internet has increased 247\% over the last five years (Fell and Shepherd 2001).

The Internet has proven to be a very powerful vehicle for distributing health information to millions of individuals since it is interactive, user-controlled, and provides a means for communicating detailed information across a vast spectrum of topics (Bernhardt et al. 2002). In an empirical study conducted by Bernhardt et al. in 2002, many of the participants made references to the "encyclopedic" value of the Internet and noted that the Internet was a source of information about "anything." Those who have access to the Internet are just a click away from over 100,000 health related websites, government health sites, professional organizations, journals, medical texts, and drug reference books, as well as over 12 million citations through PubMed, the online search service of the National Library of Medicine (Morahan-Martin 2004).

The purpose of this paper is to briefly examine consumer use of the Internet for healthcare information, discuss the questionable accuracy of this information and its implications, and finally, review a sample of healthrelated websites to examine how they can improve the quality of healthcare practices in the field. It is hoped that the review of these issues will result in similar inquiries in the future and help to monitor the accuracy of the health information provided on the Internet so that the options on the Internet can really improve the quality of healthcare. 


\section{A NEW CONSUMER SEGMENT: HEALTH INFORMATION SEEKERS}

Consumers' desires for health information on the Internet have been increasing for some time. It has been stated by Wilkins and Navarro (2001) that half of the Americans who are online were actually "health information seekers." Therefore, it is really no surprise that healthcare information is accessed more than sports, stocks, and shopping. A Harris Poll in 2001 reported that almost 100 million American adults regularly go online for information about healthcare (Wilson 2002). In fact, more people go online for medical advice on any given day than actually visit health professionals, according to figures provided by the American Medical Association (Sternberg 2003). These users seek specific health information and they want this information online.

A study by the Pew Internet \& American Life Project reported that $70 \%$ of these users seek information on behalf of a child, parent, or loved one, and $43 \%$ seek information for themselves (Fox et al. 2000). While the 70\% seek information about a specific condition, nearly $50 \%$ of them look for information about diet or nutrition (Haugh 1999). One reason why so many people are going to the Internet for health information is the belief that today's doctor-patient relationship lacks an attention to detail and personal touch that was once there in the past. The following quote from $\mathrm{CIO}$, the nation's premier publication for corporate chief information officers, explains:

Patients are out of patience. The doctor's office, never a model of efficiency, is becoming intolerable. Waiting rooms increasingly live up to their names. And when patients finally see the doctor (for three or four minutes), they're often left with not much more than a prescription and a bunch of questions they forgot to ask. That's why so many people are going to the Internet for help. (Koch 1999, p. 56)

\section{WHAT HAPPENS WHEN HEALTH INFORMATION SEEKERS USE THE INFORMATION}

Healthcare professionals are seriously concerned about the quality of information that consumers are finding on the Internet. New websites are being developed every day with very little regulation or restriction. Unfortunately the information they provide is often hard to validate, may not be current, and may be biased or fraudulent (BlissHoltz 1999).

The continuous growth in the "self-care industry" suggests that there are patients who use websites to diagnose their problems. It has been reported that as many as $18 \%$ of these patients are diagnosing or treating a medical condition on their own without consulting a doctor (Fox and Raine 2002). A problem arises if these patients diagnose their own symptoms and then pursue over-the-counter drugs that are not necessarily the best ones for their problems. When these self-diagnosing, self-treating patients fail to see their physicians, they may be relying on incorrect information, resulting in misdiagnosis and inappropriate (perhaps risky) treatment.

While the self-care sector assumes major risks, the rest of the health information seekers face serious problems too. Most people who go online for health information believe the health information they find is trustworthy (Morahan-Martin 2004). One study reported that $72 \%$ of those health information seekers believe all or most of the health information online and 69\% of them state that they have not seen any wrong or misleading health information on the Internet (Morahan-Martin 2004). On the other hand, in an exploratory study by Pucci (2003), it was stated that $32 \%$ of patients who obtained medication information from the Internet retained misleading information. Furthermore, it was noted that $43 \%$ of those who retained misleading information expressed disappointment when their physicians who refused to prescribe as expected.

Patients are increasingly taking responsibility for their health, even going so far as to suggest approaches to their physicians who are sometimes not-too-receptive (Conhaim 2003). The reluctance on the physicians' side is understandable at times. The proliferation and uncertainty around health sites have caused some physicians to distrust anything that a patient might download (Kemper 2001). In fact, many physicians have been expressing their concerns about the quality of the information on the Internet for a long while. They are concerned not only about the questionable self-treatments pursued by the patients but also about the future of their relationship with the patients when they have to explain to those patients that their Internet-based information is not as accurate as they thought it was (Kassirer 2000). 
Understandably patients find themselves in a dilemma when their physician's advice contradicts the information they obtained from the Internet. While the fundamental issue is the quality of healthcare information, the physician-patient relationship is also affected as a consequence of the questionable healthcare information available on the Internet (Pucci 2003).

\section{Monitoring The Information On The Internet}

Even though it is almost impossible to supervise the accuracy of the medical information on the Internet, there have been various efforts taken by various agencies. In 1995 some of the Internet and telemedicine experts created the Health on the Net (HON) Foundation that is now used as one of the most prestigious monitoring agencies for healthcare websites. If a website subscribes to the voluntary code of standards established by HON, and if it is secure and backed by legitimate sources, it can display the HON seal on its pages. The HON standards are about making sure that the parties who give medical advice are medical professionals (or nonprofessionals who have to disclose their lack of expertise in those related areas). The ultimate purpose is to make sure that the reader always knows the source and the purpose of the information since the websites with the HON seal have to provide detailed information about the site sponsorship and separate advertising from the editorial content.

Utilization Review Accreditation Commission (URAC) is another independent, nonprofit organization that is established to promote healthcare quality through its accreditation and certification programs. Websites are examined by using the URAC standards that cover numerous issues such as privacy and security, disclosure, development and revision of content, links to other websites (and credibility of those sites), etc. The URAC standards also look at the organization behind the website and examine if it has adequate policies and procedures, especially in terms of quality control. If a website meets these standards successfully, it is accredited by URAC and allowed to display the URAC seal.

While there are worthwhile attempts, unfortunately these foundations are not able to serve as regulatory agencies since they do not have formalized power in the industry. It is hoped that as consumers/patients get more educated in terms of these types of organizations, they begin to narrow their online search to those websites that have the proper credentials such as HON and URAC seals. By this way, those with questionable information (and lack of credentials) are eventually dropped from the search engines and lose their share of the Internet volume.

\section{Good And Not-So-Good Examples}

WebMD - The leading health website; has both HON and URAC seals; terms of conditions section states:

The contents of the WebMD Site, such as text, graphics, images, information obtained from WebMD's licensors, and other material contained on the WebMD Site ("Content") are for informational purposes only. The Content is not intended to be a substitute for professional medical advice, diagnosis, or treatment. Always seek the advice of your physician or other qualified health provider with any questions you may have regarding a medical condition. Never disregard professional medical advice or delay in seeking it because of something you have read on the WebMD Site!

InternetDrugNews.com - Owned and operated by a retired pharmaceutical rep; no HON and URAC seals; "note to visitors" states, in a rather small print:

You would be very foolish to start taking a medicine or stop taking a medicine on your own based on information you read here or any other internet website because this could cause you to become seriously ill or die.

\section{IMPROVING HEALTHCARE PRACTICES THROUGH INTERNET}

Even though there are many potential and actual problems associated with the Internet use in the field of healthcare, there is no doubt that Internet offers numerous opportunities to improve healthcare practices. Many have suggested that Internet-based practice management, catering to physician/patient needs, completing medical forms, coordinating appointments/referrals, accessing diet/nutrition information, and verifying post-operative care 
procedures, can gradually minimize the unnecessary back-office management. In addition, having user-friendly websites to address specific healthcare needs benefits both patients and practitioners. Patients are provided with valuable and comprehensive information at low cost. After all, it has been reported that many patients do not entirely comprehend the information that they are presented with in the examination room. Recognizing this problem, one would realize that offering an online medical bulletin board offers such patients an alternate outlet to use to improve their understanding of the issues without having to call their healthcare providers. With complete information available to patients at the click of a mouse, there would be fewer inbound calls made to doctors and that would result in a reduction in overhead for the physician's office in the long run (Goedert 1999; Shepherd and Fell 1998; Shinkman 2000).

\section{Few Examples Of "Rather Innovative" Online Options}

Considering the fact that there are over 100,000 health related websites operated by private companies, government agencies, professional organizations, journals, medical boards, etc., one would not have a hard time in finding somewhat creative applications. Following are just a few examples of some of the most recent and "rather innovative" additions in this field.

One good example of a new technology is a human-implantable radio frequency identification microchip. The VeriChip, sold through www.4verichip.com, is the first and only FDA-approved patient identification chip that is the size of a grain of rice. The chip is inserted under a patient's skin on the right triceps and contains a nine-digit identification code that emergency personnel can scan to identify the patient and access his/her health records by linking to a computerized databank.

Even though the VeriChip does not have a GPS capability, some consumers are still concerned about having microchip implantations. Recognizing these concerns, a Florida-based company has recently introduced the MedInfoChip through www.med-infochip.com. The Med-InfoChip is carried in a wallet, on a key ring or lanyard and once it is inserted into the USB port of a laptop or PC, it provides 64MB of information, equivalent of 44 floppy disks, about the patient's medical profile.

Going along with these options, www.webmd.com and www.medicalbridges.com offer alternate ways to consumers to keep their personal health records online. "Health Manager" service by WebMD and "Personal Health Journal" by Medical Bridges are online options that consumers use to maintain their medical lives. While patients are able to record and access their own records, they have been mostly in dark when it came to accessing to the records of hospitals. The Department of Health and Human Services has recently created a site www.hospitalcompare.hhs.gov that analyzes data submitted by more than 4000 US hospitals on the quality of care given in their facilities. The site is organized in a way that consumers can pick certain quality measures and compare the hospitals in their geographical areas with the national averages when it comes to keeping up with those quality measures.

Those consumers/patients who like to see what goes on in operation rooms now can watch a live surgical webcasts at www.or-live.com. This is a website that broadcasts various surgeries from different hospitals around the country and the viewers can e-mail their questions to those surgeons afterwards for further clarification. By this way, if a patient is scheduled to have a certain operation, he/she can see the details of a similar surgery and have his/her questions answered before undergoing the operation.

\section{CONCLUSION}

Recognizing the trend that patients have been assuming a more active role in maintaining their health, physicians need to accept the existence of the Internet and incorporate those Internet-related strategies into their practice. On the other hand, the proliferation of healthcare information on the Internet, much of which is inaccurate or incomplete, causes confusion in the minds of patients as they try to reconcile the differences between the suggestions on the Internet and the advice of their physicians. Rather than waiting to address this conflicting information, the physician-patient relationship would be better served if the physician takes the initiative in directing the patient to 
credible sources of information on the Internet. When patients express their desire to gather information on the Internet, physicians should be accepting and should recommend high-quality sites to their patients.

Even though there are many serious and legitimate concerns about the accuracy of the options provided by the Internet, it is still true that the healthcare practices can be improved by using the resources provided by the Internet. As shown by some of the innovative websites discussed above, the technology that incorporates the Internet has the potential to improve the efficiency in the marketplace and provide the consumers with better healthcare choices. It is hoped that as others review these concerns more in the future, the quality of the websites along with the information and the services they present will also be enhanced.

\section{REFERENCES}

1. Bard, Mark (2003), Web Forecast Shows Renewed Interest in Sites and Portals, Managed Healthcare Executive, (February), 42.

2. Bernhardt, Jay M., Ruth Ann Weaver Lariscy, Roxanne L. Parrott, Kami J. Silk, and Elizabeth M. Felter (2002), Perceived Barriers to Internet-Based Communication on Human Genetics, Journal of Health Communication, 7, 325-340.

3. Bliss-Holtz, James (1999), Editorial: The Nurse, the Internet, and Consumer Protection, Issues in Comprehensive Pediatric Nursing, 22 (4), 3-7.

4. Conhaim, Wallys W. (2003), Is the Doctor Online? Link-Up@ Home: Your Personal Guide to the Web, Information Today, (February), 29-31.

5. Fell, Daniel and C. David Shepherd (2001), Hospitals and the Web: A Maturing Relationship, Marketing Health Services, (Summer), 36-39.

6. Fox, S. and L. Raine (2002), Vital Decisions: How Internet Users Decide What Information to Trust When They or Their Loved Ones are Sick. Washington, D.C.: Pew Internet \& American Life Project: Online Life Report.

7. Fox, S., L. Rainie, J. Horrigan, A. Lenhart, T. Spooner, M. Burke, O. Lewis, and C. Carter (2000), The Online Healthcare Revolution: How the Internet Helps Americans Take Better Care of Themselves. Washington, D.C.: Pew Internet \& American Life Project: Online Life Report.

8. Gardner, Elizabeth (2000), Healing the Health Care Business, Internet World, 6 (10), 66-73.

9. Goedert, Joseph (1999), Partners Healthcare System Uses the Internet to Integrate Its Delivery System and Foster Collaboration Among Physicians, Health Data Management, (December), 27-35.

10. Haugh, Richard (1999), The New Consumer, H\&HN: Hospitals and Health Networks, 73 (12), 30-34, 36.

11. Kassirer, J. (2000), Patients, Physicians, and the Internet, Health Affairs, 19 (6), 115- 123.

12. Kemper, Donald W. (2001), Trust on the Health Internet, Managed Care Quarterly, 9 (1), 9-18.

13. Koch, C. (1999), Patient Power, CIO, (July), 57.

14. Morahan-Martin, Janet M. (2004), How Internet Users Find, Evaluate, and Use Online Health Information: A Cross-Cultural Review, CyberPsychology \& Behavior, 7 (5), 497-510.

15. Pucci, E. (2003), Is the Internet Transforming the Physician-Consumer Relationship? Preliminary Data in a Neurological Setting, European Journal of Neurology, 10, 192.

16. Shepherd, C. D. and D. Fell (1998), Building Web Sites that Attract Visitors, Marketing Health Services, (Spring), 44-45.

17. Shinkman, Ron (2000), Back-Office, Online, Modern Healthcare, (January), 46.

18. Sternberg, D. J. (2003), Make Life a Little Easier, Marketing Health Services, 23 (2), 44-46.

19. Vijayaraman, B. S. and G. Bhatia (2002), A Framework for Determining Success Factors of an E-Commerce Initiative, Journal of Internet Commerce, 1 (2), 63-75.

20. Wilkins, Stephen T. and Frederick H. Navarro (2001), Has the Web Really Empowered Healthcare Consumers? Marketing Health Services, (Fall), 5-10.

21. Wilson, Petra (2002), How to Find the Good and Avoid the Bad or Ugly: A Short Guide to Tools for Rating Quality of Health Information on the Internet, BMJ: British Medical Journal, 324 (7337), 598-600. 


\section{NOTES}

